\title{
Perspectivas de análise histórica da fonte epistolar*
}

\author{
Everton Vieira Barbosa**
}

Certas obras voltadas para o campo histórico comumente utilizam fontes epistolares como suporte para a pesquisa de biografias e trajetórias de vida de determinadas personagens. Avançando sobre esta proposta, o livro A carta da Condessa, escrito por Samuel Albuquerque ${ }^{1}$, amplia as perspectivas de análise histórica da fonte epistolar, uma vez que ela permite conhecer melhor os agentes históricos que se correspondem, mas também contribui na compreensão da conjuntura e do cotidiano na qual a carta e seus autores estavam inseridos.

Tomando esse caminho, o autor consegue compor um livro rico em detalhes por envolver a atuação de mulheres como preceptoras no Brasil durante o século XIX, e sensível aos olhares do leitor que é levado ao deleite do cotidiano feminino Oitocentista, bem como seus desafios, (des)afetos e deslocamentos pelo Atlântico.

Como parte de sua tese de doutorado, Samuel Albuquerque utiliza alta erudição na escrita sem perder de vista a leveza nas palavras, possibilitando ao leitor a compreensão clara de suas ideias e dos percursos e recursos utilizados para tecer a obra.

Tendo como fonte as cartas escritas e endereçadas à Luísa Margarida Portugal de Barros (1816-1891), conhecida como a Condessa de Barral e também a preceptora das filhas de D. Pedro II (1825-1891), o autor se volta para identificar quem era o destinatário da carta da Condessa, bem como quem era o jovem "V. Galvão" ao qual a escrevente mencionava no documento.

Para isso, foi necessário percorrer o Arquivo Histórico do Museu Imperial, em Petrópolis; ler autores que escreveram sobre Sergipe no século XIX e XX; acessar documentos cartorários como inventários post-mortem, registros de navios, registros de batismo e "livros de assentos" para identificar as despesas com a educação dos filhos. Livros de ficção, anúncios em periódicos brasileiros e estrangeiros, fontes imagéticas e livros de historiadores que abordam o Brasil no século $\mathrm{XIX}$, as relações de gênero, os romances, e as redes de sociabilidades também foram utilizados para tecer a obra.

O cruzamento dessas fontes foi necessário para descobrir que o destinatário da carta era Antonio Diniz de Siqueira e Mello (1812-1884), senhor do Engenho Aruary, em Santo Amaro das Brotas, e comandante superior da Guarda Nacional em Sergipe, enquanto que o jovem "V. Galvão" mencionado na carta era um de seus netos, Raimundo Diniz Dantas Galvão, que estudava em um internato francês e que estava sob os cuidados da Condessa de Barral.

O que podemos perceber no itinerário trilhado por Samuel Albuquerque foi a perspicácia do ofício historiográfico ao coligir diversas fontes e recursos a fim de rastrear e perlustrar os agentes históricos que possuíam algum vínculo com a Condessa de Barral, tecendo assim uma rede de solidariedade ampla e complexa.

Para além dessa identificação, a sapiência do autor está no horizonte de informações que seu livro permitiu agrupar, traçando os espaços de sociabilidade vivenciados pela Condessa de Barral nos anos de sua vivência no país. De mesmo modo, a obra se volta para o contexto e os entraves políticos existentes na província sergipana, bem como os trâmites e os desdobramentos de mulheres europeias que buscavam a sorte como preceptoras no Brasil.

\footnotetext{
* Recebido em19 de dezembro de 2017, aceito em 29 de junho de 2020. Resenha do livro ALBUQUERQUE, Samuel. A carta da Condessa: família, mulheres e educação no Brasil do século XIX. São Cristóvão, Editora UFS, 2016.

** Doutorando em História pela Universidade Federal Fluminense, Niterói, RJ, Brasil. Bolsista CAPES. semusico@hotmail.com / ORCID: 0000-0003-2480-7397

1 Doutor em História pela Universidade Federal da Bahia e professor da Universidade Federal de Sergipe. 
No rastro de informações agrupadas na carta da Condessa, o autor inicia a obra destacando o prestígio que Luísa Margarida Portugal de Barros adquiriu por ser filha de Domingos Borges de Barros (1780-1855), advogado, senhor de engenho, político e diplomata a serviço do Brasil na França.

A posição social de seu pai lhe rendeu a possibilidade de uma excelente formação educacional, e o casamento com Eugènie de Barral, Conde de Barral e $4^{\circ}$ Marquês de Montserrat (1810-1868), o que conferia "o status de dama casada" (Albuquerque, 2016: 86, grifo do autor), proporcionando "a liberdade de que o matrimônio oferecia às mulheres" (Del Priore, 2008:80).

Cabe ressaltar que Luísa Margarida Portugal de Barros, desde cedo, possuía uma personalidade forte. Ao "rejeitar o rico e poderoso político Miguel Calmon Du Pin e Almeida (17961865), o Marquês de Abrantes, a quem estava prometida desde os 12 anos" (Albuquerque, 2016:85) por seu pai, Luísa escolheu se casar com o conde Eugènie de Barral. Não por acaso, o autor caracteriza esta iniciativa como "um exemplo de emancipação feminina" (Albuquerque, 2016:86), já que a "boa sociedade" no Brasil Oitocentista não aprovava tal conduta por parte das mulheres.

De fato, esses elementos contribuíram para que a distinta senhora acessasse determinados espaços de prestígio social com desenvoltura e agrupasse em seu currículo os serviços prestados como dama de honra de D. Francisca de Bragança (1824-1898): a princesa de Joinville e irmã de D. Pedro II entre os anos de 1843 e 1848, e atuar como preceptora das princesas imperiais Isabel e Leopoldina, de 1856 a 1864.

Cabe salientar que entre uma e outra atuação, a Condessa de Barral tornou-se mãe de Horace-Dominique em 1854. Horace-Dominique seguiria, futuramente, os passos do pai como diplomata brasileiro. Ainda que o fato de ser mãe enquadre Luísa Margarida Portugal de Barros no tripé social da época como "mãe, esposa e dona de casa" (D'Incao, 2004; Hahner, 2012), a Condessa não deixou de atuar na esfera pública, tornando-se uma mulher de grande influência política a ponto de ela ser procurada por muitos agentes históricos com o intuito de lhe atender diversos favores e pedidos (Del Priore, 2008).

É possível, assim, compreender que os espaços de sociabilidade aos quais ela frequentava permaneciam cercados por diplomatas, políticos, militares, professores e demais agentes históricos ligados ao contexto político nacional $e$ internacional. Com tais agentes, ela soube conviver estrategicamente a fim de lhe beneficiar socialmente e lhe proporcionar uma vida tranquila ate sua morte.

Os frutos desse convívio são percebidos nas diversas redes de solidariedade, dentre elas com o destinatário de sua carta, Antonio Diniz de Siqueira e Mello, no qual Samuel Albuquerque traça um fio condutor a fim de identificar sua atuação política em Sergipe, bem como os demais agentes históricos envolvidos neste enredo.

$\mathrm{Na}$ "busca de outros dados sobre o interlocutor da condessa" (Albuquerque, 2016:23), o autor identificou que

Por via materna, Diniz era parente dos Dias Coelho e Mello, rica e poderosa família, cujo membro de maior destaque em fins da década de 1870 era o Barão da Estância (1822-1904), senhor do Engenho Escurial, em São Cristóvão, líder do Partido Liberal em Sergipe e deputado à Assembleia Geral.

O Barão da Estância era pai de Aurélia Dias Rolemberg (1863-1952), distinta senhora da elite província sergipana, na qual Samuel Albuquerque tratou de trilhar suas memórias, registradas em seu diário. Para tanto, Albuquerque cruzou as experiências de vida feminina no século XIX com a atuação das preceptoras no Brasil (Albuquerque, 2015).

Além disso, Antonio Diniz se inseriu na esfera política, sendo caracterizado como o pilar do Partido Conservador em Sergipe e, consequentemente, o representante do poder local na corte como senador. Seu prestígio pode ser confirmado na passagem de D. Pedro II e dona Teresa Cristina pela província de Sergipe, sendo acolhidos em rico banquete pelo senador $e$ toda sua família. 
Neste desdobramento, percebemos as complexas relações de poder perpassadas por Antonio Diniz de Siqueira e Mello e por membros de sua família, atuantes na política, mas também no exército, na esfera jurídica e na medicina.

Esse era o caso de Raymundo de Valois Galvão, médico, genro de Antonio Diniz de Siqueira e Mello e pai de Raimundo Diniz Dantas Galvão, o tal "V. Galvão", mencionado na epístola da Condessa de Barral, demonstrando as redes de solidariedade e com elas os diversos caminhos que a análise epistolar permite alcançar.

Dentre estes percursos, o autor destaca a utilização das epístolas na perspectiva da história da preceptoria no Brasil. Tendo como elo a atuação da Condessa de Barral como preceptora das princesas imperiais Isabel e Leopoldina, Samuel Albuquerque amplia a lupa do historiador identificando as vivências e experiências destas profissionais no Brasil.

Utilizando o tino investigativo de um verdadeiro detetive, o autor apresenta em seu livro alguns elementos normativos que imbuíam o ato da preceptoria - função também nomeada por aia, governanta ou tutora - para caracterizar as mulheres que ensinavam em uma residência familiar e/ou que serviam de acompanhantes de crianças.

Neste cabedal, Samuel Albuquerque escreve que o Brasil servia como um possível destino às mulheres europeias que buscavam "fazer a América", uma vez que os salários eram mais atrativos do que na Europa, em decorrência da saturação destas profissionais no velho continente.

Como se não bastasse a necessidade de se deslocar pelo Atlântico em busca de melhores condições de vida, essas mulheres também precisavam negociar seu translado, seus salários, bem como adaptar-se ao clima e à cultura brasileira para se estabelecerem como preceptoras no Brasil. A prova desse desafio pode ser constatada nas cartas da Condessa, e também nas epistolas da preceptora alemã Ina Von Binzer (1856-1929) que constantemente reclamava do clima tropical e da cultura local.

Ao desvelar tais situações, Samuel Albuquerque não deixa de destacar a presença das preceptoras no Brasil como um desafio à ignorância das mulheres que podiam recorrer a esse recurso a fim de se educarem e buscarem sua emancipação moral, bem como a reivindicação da equiparação entre os sexos.

Nesse sentido, o autor demonstra que uma das Atribuições da Aia, da Condessa de Barral, era fornecer às princesas Isabel e Leopoldina uma instrução que não fosse diferente da educação masculina. Ainda que tal modelo de educação se distinguisse do ensino comum destinado às mulheres no Brasil, já é possível percebemos as brechas iniciais no rompimento de um ensino pautado pelas distinções entre os papéis de gênero.

Conforme bem salienta o autor

Alguns aspectos da biografia da Condessa de Barral são reveladores das mudanças nas relações entre os sexos que se processavam, mesmo que lentamente, no século XIX. Além de subverter a tradição no que diz respeito aos "negócios do casamento", além do pragmatismo demonstrado nas negociações de sua contratação como preceptora, além de ter se tornado uma figura política importante, ela passou a interferir diretamente nos destinos da família de D. Pedro II (Albuquerque, 2016:88).

É notório o papel de destaque que Luísa Margarida Portugal de Barros possuiu nas negociações para o casamento das princesas Leopoldina e Isabel em 1864.

Ela também atuou nos desdobramentos realizados para casar seu filho com Maria de Paranaguá, filha do Visconde de Paranaguá em 1882, tendo como padrinhos Isabel e o Conde D'Eu, além de contar com a participação de D. Pedro Il e membros de todos os estratos sociais da corte (Del Priore, 2008). De fato, ela foi uma personalidade de destaque para sua época.

O livro de Samuel Albuquerque, portanto, evidencia o impacto cultural que essas mulheres exerceram na esfera privada e pública. De mesmo modo, analisa as relações de gênero, de contratação, os deslocamentos da Europa para o Brasil, as perspectivas das preceptoras, suas frustrações, seus métodos de ensino e sua atuação para além do papel de que desempenhavam nas residências e na vida de suas pupilas. A leitura do livro aqui resenhado torna possível compreender o papel desempenhado por essas mulheres, que viviam e conviviam em um ambiente muitas vezes 
diferente dos quais elas conheciam ou esperavam encontrar, onde o choque de identidade era o elemento constituinte dos (re)arranjos necessários para lidar com as adversidades e (sobre)viver em solo brasileiro.

Por fim, retornando à figura ímpar da Condessa de Barral, Samuel Albuquerque denota além da influência sobre a família imperial, sua atuação enquanto abolicionista, apesar de ser monarquista $e$ o fim de sua vida na França sem perder de vista seu prestígio $e$ as relações com os diversos agentes históricos que consolidou ao longo de sua atuação no Brasil. Tanto que a carta na qual o autor utiliza para compor sua obra foi escrita por Luísa Margarida Portugal de Barros, no ano de 1879, em Paris. Na epístola, ela responde ao seu amigo de Sergipe, Antonio Diniz de Siqueira e Mello, sobre os cuidados que ela estava tendo na educação de "V. Galvão", neto do destinatário.

Desse modo, podemos concluir que, para além de uma biografia ou identificação dos agentes históricos envolvidos em uma narrativa epistolar, Samuel Albuquerque soube utilizar a carta da Condessa para percorrer os espaços de sociabilidade de Barral, seguir os indícios da família do destinatário de sua carta, Antonio Diniz de Siqueira e Mello, para compreender os embates políticos $e$ as relações de poder na província sergipana.

Ao tomar a atuação da Condessa de Barral como preceptora das princesas imperiais Isabel e Leopoldina para destacar os desdobramentos de mulheres europeias que se deslocavam para o Brasil a fim de trabalharem como preceptoras, é possível, assim, a ampliação das perspectivas de análise histórica da fonte epistolar.

\section{Referências bibliográficas}

ALBUQUERQUE, Samuel. Nas memórias de Aurélia: cotidiano feminino no Rio de Janeiro do século XIX. São Cristóvão, Editora UFS, 2015.

D'INCAO, Maria Ângela. Mulher e família burguesa. In: DEL PRIORE, Mary (org.). História das mulheres no Brasil. $7^{a}$ ed. São Paulo, Contexto, 2004, pp.223-240.

DEL PRIORE, Mary. Condessa de Barral: a paixão do imperador. Rio de Janeiro, Objetiva, 2008.

HAHNER, June E. Honra e distinção das famílias. In: PINSKY, Carla Bassanezi; PEDRO, Joana Maria (org.). Nova História das mulheres no Brasil. São Paulo, Contexto, 2012, pp.43-64. 